\title{
Erratum to: Characterization of nanochannel delivery membrane systems for the sustained release of resveratrol and atorvastatin: new perspectives on promoting heart health
}

\author{
Juliana Sih • Shyam S. Bansal • Stefano Filippini • \\ Silvia Ferrati • Kunal Raghuwansi • Erika Zabre • \\ Eugenia Nicolov • Daniel Fine • Mauro Ferrari • \\ Ganesh Palapattu • Alessandro Grattoni
}

Received: 31 October 2012 /Accepted: 31 October 2012 /Published online: 10 November 2012

(C) Springer-Verlag Berlin Heidelberg 2012

\section{Erratum to: Anal Bioanal Chem}

DOI 10.1007/s00216-012-6484-7

We should like to call your attention to the fact that Stefano Filipini's name was misspelled in the original publication: it should be Stefano Filippini.

\footnotetext{
The online version of the original article can be found at http://dx.doi.org/ 10.1007/s00216-012-6484-7.

J. Sih $\cdot$ S. S. Bansal $\cdot$ S. Filippini $\cdot$ S. Ferrati $\cdot$ E. Zabre $\cdot$

E. Nicolov $\cdot$ D. Fine $\cdot$ M. Ferrari $\cdot$ A. Grattoni $(\varangle)$

Department of Nanomedicine, The Methodist Hospital

Research Institute,

6670 Bertner Ave., Room \# R8-216,

Houston, TX 77030, USA

e-mail: agrattoni@tmhs.org

K. Raghuwansi

NanoMedical Systems, Inc,

Austin, TX 77030, USA

M. Ferrari

Department of Medicine, Weill Cornell Medical College,

New York, NY 10065, USA

M. Ferrari

Department of Bioengineering, Rice University,

Houston, TX 77005, USA

M. Ferrari

Alliance for NanoHealth,

Houston, TX 77030, USA

G. Palapattu

Department of Urology, University of Michigan,

Ann Arbor, MI, USA
} 